\title{
Outcome after surgery for prosthetic valve endocarditis and the impact of preoperative treatment
}

\author{
Herko Grubitzsch, MD, PhD, ${ }^{\mathrm{a}}$ Andreas Schaefer, ${ }^{\mathrm{a}}$ Christoph Melzer, MD, PhD, ${ }^{\mathrm{b}}$ \\ Klaus-Dieter Wernecke, $\mathrm{MD}, \mathrm{PhD},{ }^{\mathrm{c}}$ Davide Gabbieri, $\mathrm{MD},{ }^{\mathrm{d}}$ and Wolfgang Konertz, MD, $\mathrm{PhD}^{\mathrm{a}}$
}

Objectives: This study examined the outcomes of surgery for active prosthetic valve endocarditis in a recent decade, with special interest in preoperative treatment and predictors for early and late events.

\begin{abstract}
Methods: From 2000 to 2010, a cohort of 149 consecutive patients (mean age, $64 \pm 13.9$ years; $72 \%$ were male) underwent redo-surgery for prosthetic valve endocarditis and were reviewed regarding early ( $\leq 60$ days) and late ( $>60$ days) events (death, reinfection, reoperation). Kaplan-Meier survival curves and Cox regression analysis were used to investigate the impact of preoperative intervals and predictors for events, respectively.

Results: Preoperative status was critical (European System for Cardiac Operative Risk Evaluation $>20 \%$ ) in 121 patients $(81.2 \%)$. Staphylococci were the most common infecting microorganisms $(27.5 \%)$. The median interval between onset of symptoms and diagnosis and between diagnosis and operation was 2 days (interquartile range, 1-5) and 8 days (interquartile range, 2-23), respectively. Operative mortality ( $\leq 30$ days) was $12.8 \%$. Mean follow-up was $4 \pm 2.9$ years. In 53 patients, 47 early ( 24 deaths, 14 recurrences, 9 reoperations) and 22 late events (11 deaths, 9 recurrences, 2 reoperations) occurred. Overall and event-free survivals at 10 years were $75 \% \pm 3.8 \%$ and $64 \% \pm 4.0 \%$, respectively. Freedom from recurrent infection and reoperation at 10 years were $81 \% \pm 3.6 \%$ and $91 \% \pm 2.6 \%$, respectively. In multivariate Cox regression, mechanical circulatory support, prolongation between onset of symptoms and diagnosis more than 30 days, and preoperative presence of renal failure predicted early events, and double valve replacement predicted late events.
\end{abstract}

Conclusions: Cardiac and renal function, need for double valve replacement, and preoperative treatment predicted outcomes. A prolonged interval in which patients were left untreated while symptomatic, but not prolongation of preoperative antibiotic treatment, increased risk. (J Thorac Cardiovasc Surg 2014;148:2052-9)

Prosthetic valve endocarditis (PVE), a severe complication of heart valve surgery and the most severe form of infective endocarditis (IE), is associated with significant morbidity and mortality. ${ }^{1-8}$ PVE accounts for $10 \%$ to $30 \%$ of all cases of IE and occurs in $1 \%$ to $6 \%$ of patients with valve prostheses, equally affecting mechanical and biological valves. ${ }^{3,9-11}$

Despite improvements in echocardiography, increasing knowledge, and periodically reviewed multidisciplinary guidelines, there are still difficulties in the diagnosis of PVE, because the clinical presentation is rather atypical and blood cultures and echocardiography results are frequently negative. ${ }^{5,11}$ Although there is consensus that surgery is required in complicated PVE (heart failure, severe prosthetic dysfunction, abscess/fistula, persisting

From the Klinik für Kardiovaskuläre Chirurgie, ${ }^{a}$ and Medizinische Klinik mit Schwerpunkt Kardiologie und Angiologie, ${ }^{\mathrm{b}}$ Charité - Universitätsmedizin Berlin, Berlin, Germany; CRO SOSTANA GmbH, ${ }^{\mathrm{c}}$ Berlin, Germany; and Dipartimento di Cardiochirurgia, ${ }^{\mathrm{d}}$ Hesperia Hospital, Modena, Italia.

Disclosures: Authors have nothing to disclose with regard to commercial support.

Received for publication Feb 24, 2014; revisions received April 22, 2014; accepted for publication May 9, 2014; available ahead of print June 18, 2014.

Address for reprints: Herko Grubitzsch, MD, PhD, Klinik für Kardiovaskuläre Chirurgie, Charité - Universitätsmedizin Berlin, Campus Charité Mitte, Charité-Platz 1, 10117 Berlin, Germany (E-mail: herko.grubitzsch@charite.de). $0022-5223 / \$ 36.00$

Copyright (C) 2014 by The American Association for Thoracic Surgery

http://dx.doi.org/10.1016/j.jtcvs.2014.05.025 fever, aggressive microorganisms, large vegetations), there is an ongoing discussion about general therapeutic strategies. ${ }^{4,5,11}$ For left-sided native valve IE, data from a randomized study in 76 patients with severe valve disease and large vegetations demonstrated a significant reduction of the composite end point of death from any cause and embolic events by early surgery versus conventional treatment, ${ }^{12}$ but data regarding PVE are conflicting. Lalani and colleagues ${ }^{13}$ recently showed that after adjustment for differences in clinical characteristics and survival bias in 1025 patients with PVE, early valve replacement was not associated with lower mortality compared with medical therapy in the overall cohort.

Therefore, we reviewed our experience of surgery for PVE during the most recent decade. With respect to death, recurrent infection, and reoperation, early and late events were analyzed and the impact of preoperative time delay between onset of symptoms and diagnosis and between diagnosis and operation was investigated. Furthermore, we sought to identify independent predictors for early and late events.

\section{METHODS}

\section{Patients}

With approval from our institutional Ethics Committee (EA1/032/13), we performed a retrospective review of consecutive patients who underwent 

Abbreviations and Acronyms
IE = infective endocarditis
$\mathrm{IQR}=$ interquartile range
$\mathrm{PVE}=$ prosthetic valve endocarditis

redo-surgery for PVE at the Department of Cardiovascular Surgery at Charité Campus Mitte, Berlin, between 2000 and 2010. We identified 149 patients (107 male, 42 female) with a mean age of $63.5 \pm 13.8$ years (range, 26-83). Among them, $65(43.3 \%)$ presented with early and 84 $(56.4 \%)$ presented with late PVE. The median time between first valvular surgery and reoperation was 4.1 years (interquartile range [IQR], 0.3-5.9) for all patients, 3 months (IQR, 1.7-6.7) for early PVE, and 4.9 years (IQR, 2.9-9.9) for late PVE. Primary surgery was due to IE in 26 patients $(40.0 \%)$ and 15 patients $(17.9 \%)$ with early and late PVE.

\section{Definitions}

Diagnosis of PVE was based on clinical findings (fever, inflammatory syndromes), laboratory testing (blood cultures, leukocytosis, levels of C-reactive protein and procalcitonin), results of transthoracic/transesophageal echocardiography, and intraoperative findings. ${ }^{11,14}$ According to the Guidelines of the European Society of Cardiology, PVE occurring within 1 year of primary valvular surgery was classified as early and beyond 1 year as late. ${ }^{11}$ Culture-negative endocarditis was present when no microorganism could be identified, neither in serial blood cultures nor in cultures from the explanted material despite the presence of characteristic signs for endocarditis (vegetations, periprosthetic destructions, or pus). Clinical variables were defined according to the terms of the Society of Thoracic Surgeons National Cardiac Surgery Database. For perioperative risk assessment, Society of Thoracic Surgeons and logistic European System for Cardiac Operative Risk Evaluation scores were determined. ${ }^{15,16}$ PVE predispositions were classified following the criteria proposed by Grinda and colleagues. ${ }^{17}$ Endocarditis was considered locally uncontrolled when the infectious pathology extended beyond the prosthetic valve (ie, destruction or purulent deformation of adjacent tissue, periprosthetic abscesses, and fistulas into a cardiac chamber or pericardium). Concomitant procedures were all surgical procedures performed to correct associated noninfective cardiac diseases. Events were defined by death, recurrent PVE, and reoperation. Prolonged hospital stays were classified as early if they occurred within 60 days after surgery or late if they occurred thereafter.

\section{Surgery and Postoperative Treatment}

The most common indications for surgery were vegetations greater than $10 \mathrm{~mm}(\mathrm{n}=109,73.2 \%)$, locally uncontrolled infection $(\mathrm{n}=90,60.4 \%)$, and heart failure $(\mathrm{n}=65,43.6 \%)$, which was caused by severe prosthetic valve dysfunction $(\mathrm{n}=61)$ or fistulas $(\mathrm{n}=4)$. More than 1 indication for surgery was present in 78 patients $(52.3 \%)$.

All operations were performed through a median sternotomy using an oscillating saw. Cardiopulmonary bypass, installed via cannulation of the distal ascending aorta, the aortic arch or femoral artery, and the right atrium or femoral vein, was used with systemic normothermia or mild hypothermia $\left(32^{\circ} \mathrm{C}\right)$ if a patent thoracic artery bypass was present. Myocardial protection was achieved with intermittent antegrade blood cardioplegia. Previously implanted prostheses were removed in total, and abscesses and fistulas were thoroughly debrided. The remaining tissue was disinfected using povidone-iodine solution. In the presence of large abscess cavities, fistulas, or tissue defects, a pericardial (autologous, bovine or equine) patch repair was performed. The choice for the new prosthesis was at the discretion of the surgeon. Concomitant procedures, if needed, were performed according to standard techniques. Infected intravascular catheters were removed before surgery.
All patients underwent intravenous antibiotic/antimycotic treatment for at least 6 weeks postoperatively. Antibiotic regimen was directed by microbiological findings and based on guidelines. ${ }^{11}$ In the case of culture-negative PVE, an empirical, broad-range, antibiotic treatment was initiated, usually consisting of vancomycin, rifampicin, and gentamycin.

\section{Follow-up}

Follow-up was obtained by telephone interviews and mail questionnaire. Complications were confirmed by contact with the patient's cardiologist or family physician. In case of rehospitalizations, copies of the medical reports were obtained.

\section{Statistical Analysis}

Categoric variables are reported as absolute and relative frequencies. For continuous data, means and standard deviations or medians and interquartile ranges were calculated. For comparison of microbiological findings in patients presenting with early and late PVE, the Fisher chi-square test was used. Overall and event-free survival, and freedom from recurrence and reoperation were analyzed using Kaplan-Meier curves and log-rank test. A Cox regression analysis was used to identify predictors for early and late events. First, a univariate approach evaluating all possible risk factors was applied, followed by a multiple Cox regression (backward elimination; likelihood ratio) of all significant variables. Aikaike's information criterion was used to assess the goodness of fit. The assumption of proportional hazard was checked. All the statistical analyses were performed using SPSS Statistics 19 for Windows (SPSS Inc, Chicago, Ill) and supervised by an independent statistician (K.-D.W.). Because of the exploratory nature of the study, no adjustment for multiple testing was carried out.

\section{RESULTS}

\section{Baseline Characteristics}

Preoperative status was critical in a significant number of patients (Table 1): sepsis $(n=23)$, shock $(n=14)$, acute renal failure $(\mathrm{n}=17)$, and the necessity of mechanical ventilation $(\mathrm{n}=17)$ and pharmacologic circulatory support $(\mathrm{n}=19)$. Accordingly, logistic European System for Cardiac Operative Risk Evaluation was greater than $20 \%$ in 121 patients $(81.2 \%)$. A total of 49 patients $(32.9 \%)$ sustained 1 or multiple embolic complications involving 1 or more systems: brain including retina $(\mathrm{n}=28)$, mesenteric circulation including spleen $(\mathrm{n}=14)$, upper or lower limbs $(\mathrm{n}=11)$, kidneys $(\mathrm{n}=6)$, and coronary arteries $(\mathrm{n}=5)$. Extracardiac infection was present in 31 patients $(20.8 \%)$, including pneumonia or pulmonic abscess $(n=7)$, skin or soft tissue infection $(n=6)$, urogenital infection $(n=5)$, spondylodiscitis and nonsternal osteomyelitis $(\mathrm{n}=5)$, intra-abdominal infection or abscess $(n=3)$, surgical site infection after primary cardiac surgery $(n=3)$, and infected intravascular catheters $(n=2)$. One or more extracardiac predispositions for IE were found in 51 patients $(39.6 \%)$, including diabetes $(\mathrm{n}=38)$, intravenous drug abuse $(\mathrm{n}=9)$, alcoholism $(\mathrm{n}=6)$, corticotherapy $(n=4)$, chemotherapy $(n=3)$, leukemia $(n=1)$, and chronic hemodialysis $(\mathrm{n}=4)$.

\section{Preoperative Time Intervals}

Median time intervals between onset of symptoms and diagnosis and between diagnosis and operation were 
TABLE 1. Baseline characteristics and operative data

\begin{tabular}{|c|c|c|}
\hline Parameter & n $(\%)$ & Mean \pm SD \\
\hline Age $(y)$ & & $63.5 \pm 13.85$ \\
\hline Age $>70 y$ & $58(38.9)$ & \\
\hline Male gender & $107(71.8)$ & \\
\hline $\operatorname{BSA}\left(\mathrm{m}^{2}\right)$ & & $1.9 \pm 0.21$ \\
\hline NYHA class I-II & $65(43.6)$ & \\
\hline NYHA class III-IV & $84(56.4)$ & \\
\hline LVEF & & $0.51 \pm 0.12$ \\
\hline LVEF $<0.40$ & $21(14.1)$ & \\
\hline STS score & & $17.9 \pm 10.82$ \\
\hline euroSCORE & & $41.5 \pm 24.18$ \\
\hline euroSCORE $>20 \%$ & $121(81.2)$ & \\
\hline euroSCORE $>40 \%$ & $66(44.3)$ & \\
\hline Early PVE & $65(43.6)$ & \\
\hline Late PVE & $84(56.4)$ & \\
\hline Sepsis & $23(15.2)$ & \\
\hline Shock & $14(9.4)$ & \\
\hline Cardiogenic & $6(4.0)$ & \\
\hline Septic & $8(5.4)$ & \\
\hline Preoperative ventilatory support & $17(11.4)$ & \\
\hline $\begin{array}{l}\text { Preoperative circulatory support } \\
\text { (catecholamines) }\end{array}$ & $19(12.8)$ & \\
\hline Preoperative renal failure & $17(11.4)$ & \\
\hline Chronic hemodialysis & $4(2.7)$ & \\
\hline Preoperative neurologic deficits & $36(24.2)$ & \\
\hline Previous embolic events & 49 (32.9) & \\
\hline Isolated & $32(21.5)$ & \\
\hline Multiple & $17(11.4)$ & \\
\hline Pulmonary hypertension & $22(14.8)$ & \\
\hline Previous myocardial infarction & $9(6.0)$ & \\
\hline Diabetes & $38(25.5)$ & \\
\hline COPD & $29(25.5)$ & \\
\hline Arterial hypertension & $67(45.0)$ & \\
\hline \multicolumn{3}{|l|}{ Operative priority } \\
\hline Emergency & $47(31.5)$ & \\
\hline Urgent & $55(36.9)$ & \\
\hline Elective & $47(31.5)$ & \\
\hline \multicolumn{3}{|l|}{ Procedural figures } \\
\hline Operation time (min) & & $260 \pm 88.3$ \\
\hline CPB time (min) & & $149 \pm 62.4$ \\
\hline ACC time (min) & & $112 \pm 44.3$ \\
\hline \multicolumn{3}{|l|}{ Surgical procedures } \\
\hline Aortic valve surgery & $92(61.7)$ & \\
\hline Mechanical prosthesis & $11(12.0)$ & \\
\hline Bioprosthesis & $80(87.0)$ & \\
\hline Autograft (Ross procedure) & $5(5.4)$ & \\
\hline Mitral valve surgery & $42(28.2)$ & \\
\hline Mechanical prosthesis & $6(14.3)$ & \\
\hline Bioprosthesis & $36(85.7)$ & \\
\hline Double valve surgery & $15(10.1)$ & \\
\hline Mechanical prosthesis & $2(13.3)$ & \\
\hline Bioprosthesis & $13(86.7)$ & \\
\hline Concomitant procedures & $7(4.7)$ & \\
\hline Mitral valve repair & $1(14.3)$ & \\
\hline Tricuspid valve repair & $1(14.3)$ & \\
\hline CABG & $5(71.4)$ & \\
\hline
\end{tabular}

TABLE 1. Continued

\begin{tabular}{lrr}
\hline \multicolumn{1}{c}{ Parameter } & n $(\%)$ & Mean \pm SD \\
\hline Mechanical circulatory support & $14(9.4)$ & \\
IABP & $11(7.4)$ & \\
LVAD & $1(0.7)$ & \\
RVAD & $2(1.3)$ & \\
\hline
\end{tabular}

$A C C$, Aortic crossclamp time; $B S A$, body surface area; $C A B G$, coronary artery bypass grafting; $C O P D$, chronic obstructive pulmonary disease; $C P B$, cardiopulmonary bypass time; euroSCORE, European System for Cardiac Operative Risk Evaluation; $I A B P$, intra-aortic balloon pump; $L V A D$, left ventricular assist device; $L V E F$, left ventricular ejection fraction; $P V E$, prosthetic valve endocarditis; $R V A D$, right ventricular assist device; SD, standard deviation; NYHA, New York Heart Association; STS, The Society of Thoracic Surgeons.

2 days (interquartile range 1-5) and 8 days (2-23), respectively. The diagnosis of PVE was established within 2 weeks after the onset of symptoms in 130 patients $(87.2 \%)$ and later in 19 patients $(12.8 \%)$. Surgery was performed within 2 weeks after diagnosis of PVE in 98 patients $(65.8 \%)$ and later in 51 patients $(34.2 \%)$. The interval between onset of symptoms and diagnosis was more than 30 days in 8 patients, and the interval between diagnosis and operation was more than 30 days in 23 patients.

\section{Microbiological Findings}

The results of blood and valve cultures are listed in Table 2. Staphylococci were the most common infecting microorganisms, in both early and late PVE. In late PVE, Streptococci and Enterococcus faecalis were frequently present. Problematic germs (Staphylococci, gram-negative bacteria, fungi, multiresistent organisms) caused uncontrolled infection in 52 patients $(34.9 \%)$. Despite repeated blood cultures, intraoperative swabs, examination of the explanted valves, serodiagnostics, and techniques of cellular microbiology, endocarditis was culture-negative in $35.6 \%$ of patients.

\section{Operation and Perioperative Course}

Previous valvular surgery comprised 6 mitral valve reconstructions and 164 aortic, mitral, or double valve replacements, including 113 bioprostheses, 45 mechanical valves, and 6 Ross procedures. The recent operations data are summarized in Table 1 . Only $31.5 \%$ were elective procedures. In the majority of patients $(86.6 \%)$, bioprostheses were used, in aortic position predominantly stentless valves $(91.4 \%)$. The implantation technique of stentless aortic valve prostheses was subcoronary in 51 patients, inclusion cylinder in 33 patients, and root replacement in 9 patients. For reconstruction of perivalvular tissue defects, pericardial patch repair was performed in 12 patients.

Five patients died intraoperatively, and 14 patients died within 30 days after surgery, resulting in an overall operative mortality ( $\leq 30 \mathrm{~d}$ ) of $12.8 \%$. In 4 moribund patients, intraoperative death occurred because of unfavorable cardiac or septic shock even before cardiopulmonary 
TABLE 2. Microbiological findings

\begin{tabular}{|c|c|c|c|}
\hline Microorganism & $\begin{array}{c}\text { Total } \\
\text { population } \\
\mathbf{n}=149\end{array}$ & $\begin{array}{c}\text { Early } \\
\text { PVE } \\
n=65\end{array}$ & $\begin{array}{c}\text { Late } \\
\text { PVE } \\
\mathbf{n}=\mathbf{8 4}\end{array}$ \\
\hline Staphylococcus species, n (\%) & $41(27.5)$ & $23(35.4)$ & $18(21.4)^{*}$ \\
\hline Staphylococcus aureus (NMR) (n) & 16 & 6 & 10 \\
\hline $\operatorname{MRSA}(\mathrm{n})$ & 3 & 2 & 1 \\
\hline Staphylococcus epidermidis (n) & 16 & 10 & 6 \\
\hline Staphylococcus hominis $(\mathrm{n})$ & 5 & 5 & - \\
\hline Staphylococcus lugdunensis (n) & 1 & - & 1 \\
\hline Streptococcus species, n (\%) & $24(16.1)$ & $8(12.3)$ & $16(19.0)$ \\
\hline Streptococcus viridans $(\mathrm{n})$ & 11 & 4 & 7 \\
\hline Streptococcus agalactiae (n) & 1 & - & 1 \\
\hline Streptococcus bovis $(\mathrm{n})$ & 6 & 2 & 4 \\
\hline Streptococcus pyogenes $(\mathrm{n})$ & 5 & 1 & 4 \\
\hline Streptococcus dysgalactiae (n) & 1 & 1 & - \\
\hline Enterococcus faecalis, n (\%) & $20(13.4)$ & $4(6.2)$ & $16(19.0) \dagger$ \\
\hline Enterobacter cloacae, n (\%) & $1(0.7)$ & - & $1(1.2)$ \\
\hline Pseudomonas aeruginosa, $\mathrm{n}(\%)$ & $2(1.3)$ & $1(1.5)$ & $1(1.2)$ \\
\hline Escherichia coli, n (\%) & $1(0.7)$ & - & $1(1.2)$ \\
\hline Klebsiella pneumoniae, n (\%) & $1(0.7)$ & - & $1(1.2)$ \\
\hline $\begin{array}{l}\text { ESBL-producing Gram-negative } \\
\text { pathogens, } \mathrm{n}(\%)\end{array}$ & $3(2.0)$ & $2(3.1)$ & $1(1.2)$ \\
\hline Corynebacterium jeikeium, n (\%) & $2(1.3)$ & $1(1.5)$ & $1(1.2)$ \\
\hline Candida species, n $(\%)$ & $3(2.0)$ & - & $3(3.6)$ \\
\hline Multiple microorganisms, $\mathrm{n}(\%)$ & $4(2.7)$ & $1(1.5)$ & $3(3.6)$ \\
\hline Culture-negative endocarditis, n (\%) & $53(35.6)$ & $25(38.5)$ & $28(33.3)$ \\
\hline
\end{tabular}

bypass was installed ( 3 patients) and uncontrollable bleeding (1 patient). The main causes of postoperative death were multiple organ failure $(n=7)$, refractory cardiac failure $(\mathrm{n}=5)$, and uncontrolled sepsis $(\mathrm{n}=2)$. Mean intensive care unit and hospital stays were $11.0 \pm 20.8$ days and $37.3 \pm 30.2$ days, respectively. Perioperative morbidity was significant, and 117 patients $(78.5 \%)$ experienced at least 1 disease or surgery-related complication. These included reoperation $(\mathrm{n}=9)$ due to recurrent PVE $(\mathrm{n}=14)$, acute renal failure requiring hemodialysis $(\mathrm{n}=38)$, pulmonary failure requiring prolonged mechanical ventilation $(\mathrm{n}=30)$, atrial fibrillation $(\mathrm{n}=30)$, nosocomial pneumonia $(\mathrm{n}=14)$, complete heart block requiring permanent pacemaker implantation $(n=12)$, transient delirium $(n=8)$, and permanent $(n=6)$ or transient $(n=4)$ neurologic events. Reexploration for bleeding or pericardial tamponade was necessary in 14 patients. Surgical site infection occurred in 3 patients.

\section{Event-Related Outcome}

Length of follow-up was $4 \pm 2.9$ years (range, 0-10.3 years) and $96 \%$ complete (6 patients were lost). According to the definitions given earlier, 69 events (47 early, 22 late) occurred in 53 patients, including 35 deaths (24 early, 11 late), 23 recurrences (14 early, 9 late), and 11 reoperations
(9 early, 2 late). The causes of deaths were cardiac in 22 patients (intraoperative death in 5, heart failure in 7 , recurrent endocarditis in 5, sudden cardiac death in 3, myocardial infarction in 2), noncardiac in 10 patients (multiple organ failure in 7 , intractable sepsis in 2 , coagulopathy in 1), and unknown in 5 patients. Recurrent endocarditis (18 cases occurred within 1 year) was treated with antibiotics alone in 12 patients ( 3 deaths) and by redo surgery in 11 patients ( 2 deaths). The offending microorganism was the same as in the first infection in 10 patients, different in 4 patients, and culture-negative in 9 patients. All reoperations were performed for recurrent endocarditis. Figure 1 shows the actuarial results for these events.

\section{Association Between Preoperative Treatment and Occurrence of Events}

Events occurred more frequently when PVE was diagnosed more than 30 days after the onset of symptoms, whereas surgery more than 30 days after diagnosis did not influence the event rate (Figure 2). It has to be stressed that no patient who experienced more than a 30-day delay between onset of symptoms and diagnosis was receiving medical treatment for PVE, whereas almost all patients $(\mathrm{n}=21,91.3 \%)$ who underwent operation more than 30 days after PVE was detected were treated with antibiotics. In the latter group, there was no clear indication for surgery at the time of diagnosis. However, during the course of medical treatment, persistent infection characterized by increasing or persistent vegetations (14 patients, 60.9\%) and locally uncontrolled infection (9 patients, 39.1\%) evolved and eventually required surgery.

\section{Risk Factors for Early and Late Events}

According to Cox regression analysis, the risk factors for early and late events are shown in Table 3. Because mechanical circulatory support, prolongation between onset of symptoms and diagnosis more than 30 days, and preoperative presence of renal failure are independent risk factors for early events, we found that advanced heart failure, untreated PVE, and secondary organ damage are significant predictors for early outcome. On the other hand, the long-term outcome is determined by extensive valvular involvement, because patients requiring double valve replacement were at higher risk for late events. For other variables, in particular age, gender, causative microorganism, early or late PVE, locally uncontrolled infection, aortic crossclamp time, and type of prosthesis, we were unable to detect any association with increased risk.

\section{Comment}

This study presents the results of surgery for PVE in the most recent decade. The outcome was limited by death, recurrent endocarditis, and need for reoperation occurring 
Overall Survival

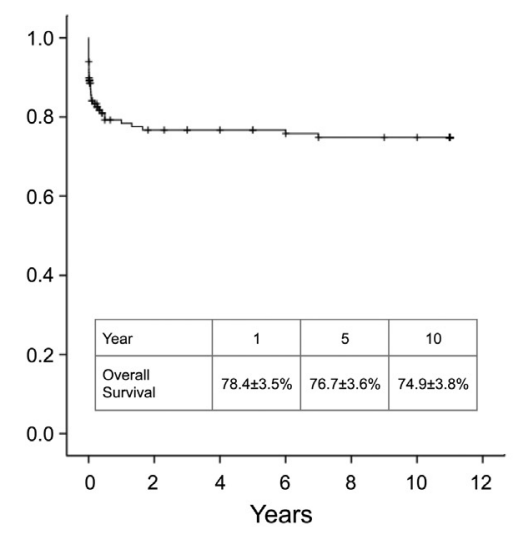

\begin{tabular}{|l|c|c|c|c|c|c|}
\hline Time (years) & 0 & 2 & 4 & 6 & 8 & 10 \\
\hline Pat. at risk (n) & 149 & 89 & 85 & 82 & 79 & 77 \\
\hline Events (n) & 8 & 32 & 32 & 33 & 34 & 34 \\
\hline
\end{tabular}

Freedom from Recurrence

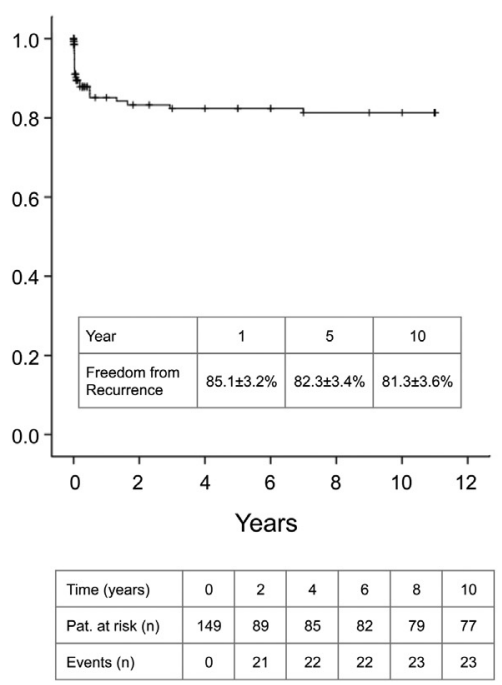

Event-free Survival

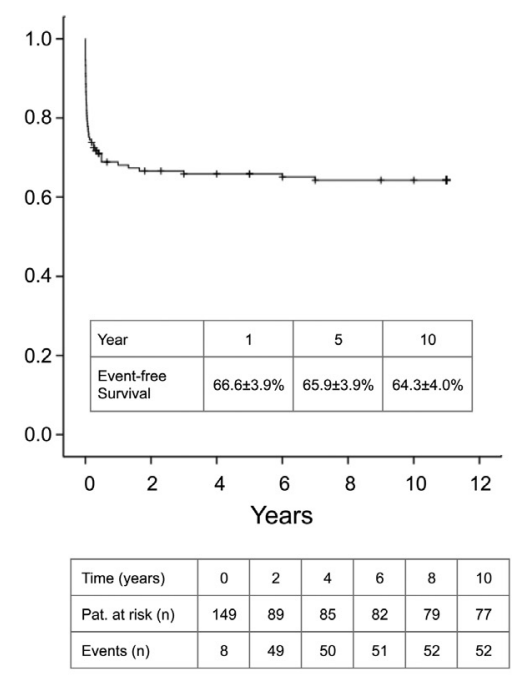

Freedom from Re-Operation

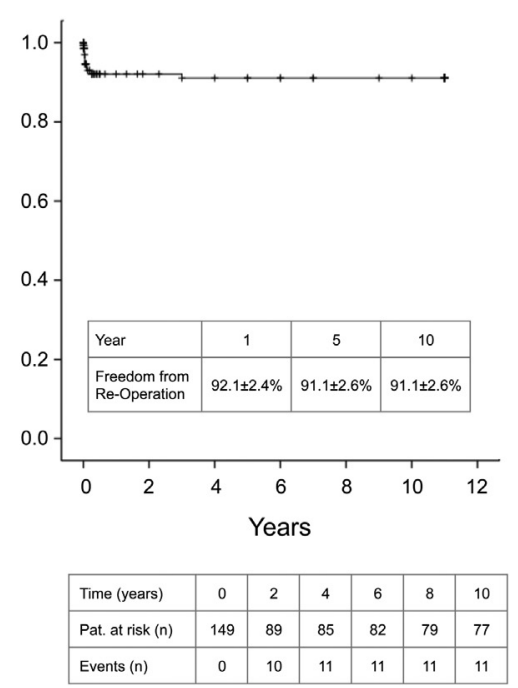

FIGURE 1. Outcome after surgery for PVE for all patients. Kaplan-Meier curves for overall and event-free survival and for freedom from recurrent PVE and reoperation are depicted.

predominantly early after operation ( $\leq 60$ days). Compared with the early postoperative period, the incidence of such events was less than half at long-term follow-up ( $>60$ days, up to 10 years). Several risk factors could be identified: need for mechanical circulatory support, prolongation between onset of symptoms and diagnosis more than 30 days, and preoperative presence of renal failure as predictors for early events and need for double valve replacement as a predictor for late events.

\section{Predictors for Early Events}

The 3.8-fold increase of risk of early events by need for mechanical circulatory support reflects the impact of severe cardiac failure, which is known as an important risk factor not only in patients undergoing surgery for prosthetic or native valve $\mathrm{IE},{ }^{3,5,6,13,18-20}$ but also for cardiac surgery in general. ${ }^{16}$ Among other independent risk factors, such as emergency operation, preoperative catecholamines, mitral valve replacement, and age, mechanical circulatory support was previously shown to be the strongest predictor for early mortality $\left(<30\right.$ days) after surgery for PVE. ${ }^{20}$

Although the diagnosis of PVE was established within 2 weeks after the presence of symptoms in the majority of our patients, prolongation of this interval more than 30 days - correlating with duration of untreated PVE more than 30 days - was associated with a similar increase 
Interval

Onset of Symptoms - Diagnosis

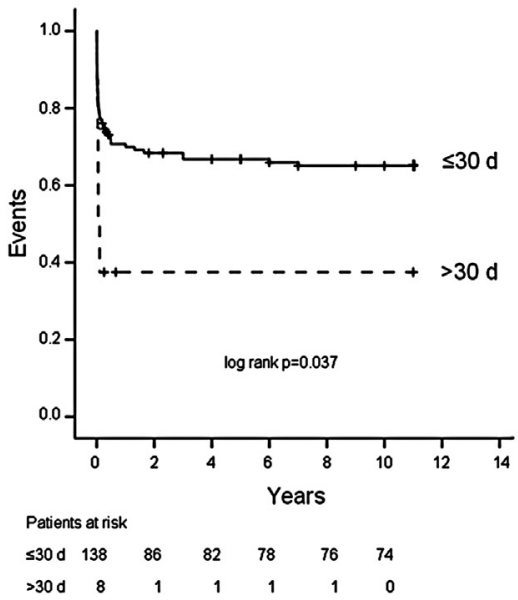

Interval

Diagnosis - Surgery

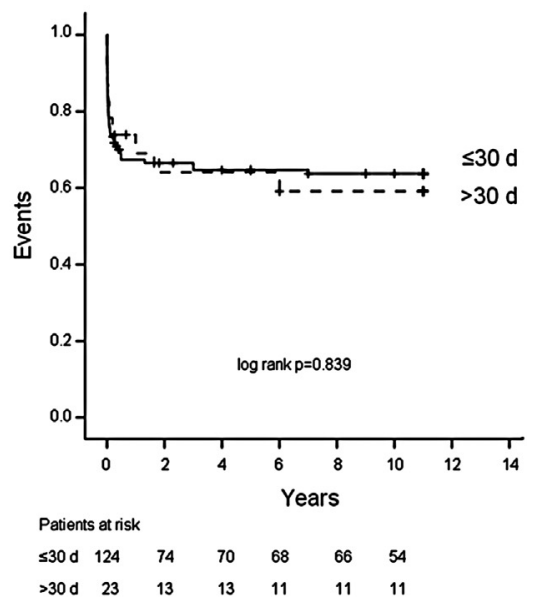

FIGURE 2. Association between preoperative treatment and events. Kaplan-Meier curves show comparison of event rates according to preoperative intervals. Almost all patients were receiving medical treatment with antibiotics between diagnosis and surgery, whereas no patient was between onset of symptoms and diagnosis.

of risk (Table 3). On the other hand, medical treatment of PVE more than 30 days until strong indications for surgery were present (interval between diagnosis and operation $>30$ days) did not add any risk. This finding is in line with recently published results of the International Collaboration

TABLE 3. Risk factors for early and late events

\begin{tabular}{|c|c|c|c|}
\hline & HR & $95 \%$ CI & $\boldsymbol{P}$ \\
\hline \multicolumn{4}{|l|}{ Early events ( $\leq 60 \mathrm{~d})$} \\
\hline \multicolumn{4}{|l|}{ Univariate Cox regression } \\
\hline Mechanical circulatory support & 4.931 & $2.288-10.630$ & $<.001$ \\
\hline NYHA class IV & 4.084 & $1.818-9.174$ & .001 \\
\hline Preoperative ventilatory support & 3.124 & $1.514-6.445$ & .001 \\
\hline Shock & 3.104 & $1.422-6.779$ & .003 \\
\hline Emergency operation & 3.084 & $1.290-7.313$ & .001 \\
\hline Interval symptoms-diagnosis $>30 \mathrm{~d}$ & 3.059 & $1.190-7.865$ & .015 \\
\hline Preoperative renal failure & 3.005 & $1.535-5.881$ & .001 \\
\hline Preoperative circulatory support & 2.804 & $1.360-5.779$ & .004 \\
\hline LVEF $<0.40$ & 2.727 & $1.174-4.394$ & .012 \\
\hline Preoperative lactate $<2 \mathrm{mmol} / \mathrm{L}$ & 2.400 & $1.185-4.861$ & .012 \\
\hline euroSCORE $>40 \%$ & 1.885 & $1.002-3.591$ & .050 \\
\hline CPB time & 1.005 & $1.001-1.009$ & .026 \\
\hline \multicolumn{4}{|l|}{ Multivariate Cox regression } \\
\hline Mechanical circulatory support & 3.823 & $1.742-8.389$ & .001 \\
\hline Interval symptoms-diagnosis $>30 \mathrm{~d}$ & 3.130 & $1.202-8.149$ & .019 \\
\hline Preoperative renal failure & 2.322 & $1.113-4.845$ & .025 \\
\hline \multicolumn{4}{|l|}{ Late events $(>60 \mathrm{~d})$} \\
\hline \multicolumn{4}{|l|}{ Univariate Cox regression } \\
\hline Interval symptoms, surgery $>90 \mathrm{~d}$ & 4.391 & $1.016-19.591$ & .034 \\
\hline Double valve replacement & 4.005 & $1.368-11.730$ & .006 \\
\hline \multicolumn{4}{|l|}{ Multivariate Cox regression } \\
\hline Double valve replacement & 4.446 & $1.568-12.608$ & .005 \\
\hline
\end{tabular}

$C I$, Confidence interval; $C P B$, cardiopulmonary bypass; euroSCORE, European System for Cardiac Operative Risk Evaluation; $H R$, hazard ratio; $L V E F$, left ventricular ejection fraction; NYHA, New York Heart Association. on Endocarditis-Prospective Cohort Study, a prospective, multinational, observational study in 1025 patients with PVE demonstrating that early surgery (median time from admission to surgery 8 days) was not associated with lower mortality compared with medical therapy unless clear indications for surgery, such as valve regurgitation, vegetation, and dehiscence or paravalvular abscess/fistula, were present. ${ }^{13}$ However, Lalani and colleagues ${ }^{13}$ did not evaluate the duration of preoperatively untreated PVE and the potential benefit of earlier compared with later surgery, which may influence the outcome. Furthermore, they only analyzed outcome regarding mortality but did not report results with respect to recurrence of PVE and reoperation.

The diagnosis of PVE is difficult because the clinical presentation is rather atypical and the results of blood cultures and echocardiography are more frequently negative. ${ }^{5}$ Even transesophageal echocardiography, which is mandatory in the assessment of PVE, initially may be falsely negative in true PVE. ${ }^{5}$ Considering these results (Figure 2), it has to be concluded that initiating antibiotic treatment in the case of clinical suspicion of PVE makes more sense than merely waiting until diagnosis is confirmed by repeated echocardiography. Medical treatment seems to be appropriate as long as clear indications for surgery (heart failure, uncontrolled infection, prevention of embolism) are missing.

In this study, preoperative renal failure evolved as the third independent risk factor for early events. In the context of IE, renal dysfunction can be regarded as end-organ damage due to congestive heart failure and low cardiac output, renal embolization, or immune complex glomerulonephritis. Consequently, renal complications occur in $5 \%$ to $10 \%$ of patients with IE and renal failure was demonstrated to be a significant predictor of early 
mortality in patients undergoing surgery for native or prosthetic IE. 6 ,20-23

\section{Predictors for Late Events}

We found double valve replacement as an independent predictor for late events. Because all patients undergoing double valve surgery presented with IE affecting both valves, this result emphasizes the importance of extensive valvular infection. Accordingly, we have previously found that apart from older age and preoperative renal failure, concomitant mitral valve surgery due to endocarditis was an independent predictor of late death after surgery for aortic valve IE. ${ }^{23}$ There are few reports analyzing predictors for long-term outcome after surgery for PVE. In contrast to our results, available data from studies on surgery for IE could not demonstrate double valve replacement as a risk factor for long-term outcome. ${ }^{21,24}$ However, within these cohorts, (1) only $30 \%$ to $43 \%$ of patients presented with PVE and (2) information on how many double valve procedures were performed for double valve infection was not given. ${ }^{21,24}$

\section{Prognostic Implications Considering Survival, Recurrent Infection, and Reoperation}

Consistent with recent reports from Sweden and the Cleveland Clinic, reporting an early mortality (30 days) after surgery for PVE of $14 \%$ and $13 \%$, respectively, our study found a decrease in operative mortality compared with the rates in previous eras. ${ }^{25}$ Nevertheless, mortality remains a significant issue and can reach $20 \%$ to $30 \%$ if preoperative status is critically limited or PVE is more complicated..$^{4-6,9,20}$ Several factors have been associated with increased mortality, of which complicated PVE and staphylococcal infections are the most powerful markers. ${ }^{5}$ As in our patients, staphylococci are the most common causative microorganisms for PVE today. ${ }^{4,6-8,13,20}$ Overall survival at 5 years was $76.7 \%$ in this study, which is similar to that in recent reports from other groups. ${ }^{7,8}$ Considering that an increasing amount of patients with IE have PVE, these long-term results are promising because they do not significantly differ from native IE. ${ }^{7,8}$ In contrast to other reports, ${ }^{7,8,20}$ survival remained stable beyond 5 years in our patients and was approximately $75 \%$ at 10 years.

In regard to the long-term prognosis of PVE, event-free survival, considering at least the incidence of reinfection and reoperation in addition to mortality, is more realistic (Figure 1). The majority of such events occurred within the first year after operation, confirming observations from Musci and colleagues. ${ }^{20}$ The rate of reinfections and reoperations after surgery for PVE has not been frequently reported. At 10 years, Musci and colleagues ${ }^{20}$ report freedom from reoperation due to reinfection of $85.8 \%$ and $92.1 \%$ after surgery for early and late PVE, respectively. Comparably, in this study freedom from reoperation, all redo procedures were due to recurrent endocarditis, was $91 \%$ at 10 years.

Obviously, not all cases of recurrent endocarditis require reoperation, although the earlier reinfection occurs the more frequently repeat surgery will be necessary. Thus, $52 \%$ of our patients who presented with reinfection, but missed any clear indication for surgery, were successfully treated medically. For the long-term perspective, however, not only late reinfection or de novo infection but also prosthetic valve dysfunction, in particular structural deterioration of bioprostheses, and other reasons have to be considered indications for reoperation. ${ }^{24}$

The optimal substitute to be used for replacement of an infected valvular prosthesis is still a matter of debate. Studies comparing mechanical and biological prostheses for $\mathrm{IE},{ }^{22}$ homografts and conventional prostheses for aortic $\mathrm{IE}^{26}$ or homografts and composite prostheses for aortic $\mathrm{PVE}^{27}$ demonstrated that operative mortality, early and long-term survival, and risk of reinfection and reoperation were similar and therefore independent of the type of substitute implanted. In particular, aortic valve homografts are believed to be ideally suited to treat PVE with aortic root abscess. ${ }^{17,20,28,29}$ However, for patients requiring second reoperation for reinfection, $61.1 \%$ presented with aortic root abscess at first reoperation, which was treated by homograft aortic root replacement. ${ }^{20}$ Moreover, although Musci and colleagues ${ }^{20}$ used homograft aortic root replacement in $38.4 \%$ of their patients, the reoperation rate is identical to that found in this study, in which stentless bioprostheses were predominantly used for aortic valve replacement. In general, the benefit of surgery seems to be more related to the ability to extirpate all infected tissue than to the prosthesis used for replacement itself. ${ }^{24}$

\section{Study Limitations}

Because of the retrospective nature of the present study, it has limitations because no patient was assigned to specific treatment. The conclusion that preoperative treatment predicts outcomes is limited by the small patient number. Furthermore, it reports results from a single surgical center, and although this is part of a huge university hospital, patients have been referred from different hospitals. Also, no solely medically treated cohort was available whose outcome could be compared with this surgical cohort. However, all patients were included consecutively during the most recent decade and followed for a sufficiently long time period.

\section{CONCLUSIONS}

Surgery for PVE is frequently required and remains associated with a significant risk for not only death but also reinfection and reoperation. Cardiac and renal function, the need for double valve replacement, and 
preoperative treatment predicted outcomes. The risk, in particular for early events, increased significantly if the preoperative interval in which patients were symptomatic but not treated exceeded 30 days, whereas preoperative medical treatment with antibiotics-as long as no clear indication for surgery was present-for more than 30 days was not associated with increased risk.

\section{References}

1. Lytle BW, Priest BP, Taylor PC, Loop FD, Sapp SK, Stewart RW, et al. Surgical treatment of prosthetic valve endocarditis. J Thorac Cardiovasc Surg. 1996;111: 198-210.

2. Akowuah EF, Davies W, Oliver S, Stephens J, Riaz I, Zadik P, et al. Prosthetic valve endocarditis: early and late outcome following medical or surgical treatment. Heart. 2003;89:269-72.

3. Habib G, Tribouilloy C, Thuny F, Giorgi R, Brahim A, Amazouz M, et al. Prosthetic valve endocarditis: who needs surgery? A multicentre study of 104 cases. Heart. 2005;91:954-9.

4. Wang A, Athan E, Pappas PA, Fowler VG Jr, Olaison L, Paré C, et al. Contemporary clinical profile and outcome of prosthetic valve endocarditis. JAMA. 2007;297:1354-61

5. Habib G, Thuny F, Avierinos JF. Prosthetic valve endocarditis: current approach and therapeutic options. Prog Cardiovasc Dis. 2008;50:274-81.

6. Alonso-Valle H, Fariñas-Alvarez C, García-Palomo JD, Bernal JM, Martin-Durán R, Gutiérrez Diez JF, et al. Clinical course and predictors of death in prosthetic valve endocarditis over a 20-year period. J Thorac Cardiovasc Surg. 2010;139:887-93.

7. Manne MB, Shrestha NK, Lytle BW, Nowicki ER, Blackstone E, Gordon SM, et al. Outcomes after surgical treatment of native and prosthetic valve infective endocarditis. Ann Thorac Surg. 2012;93:489-94.

8. Edlin P, Westling K, Sartipy U. Long-term survival after operations for native and prosthetic valve endocarditis. Ann Thorac Surg. 2013;95:1551-6.

9. Calderwood SB, Swinski LA, Karchmer AW, Waternaux CM, Buckley MJ. Prosthetic valve endocarditis. Analysis of factors affecting outcome of therapy. J Thorac Cardiovasc Surg. 1986;92:776-83.

10. Vongpatanasin W, Hillis LD, Lange RA. Prosthetic heart valves. $N$ Engl J Med. 1996;335:407-16.

11. Habib G, Hoen B, Tornos P, Thuny F, Prendergast B, Vilacosta I, et al. Guidelines on the prevention, diagnosis, and treatment of infective endocarditis (new version 2009). The task force on the prevention, diagnosis, and treatment of infective endocarditis of the European Society of Cardiology (ESC). Eur Heart J. 2009; 30:2369-413.

12. Kang DH, Kim YJ, Kim SH, Sun BJ, Kim DH, Yun SC, et al. Early surgery versus conventional treatment for infective endocarditis. N Engl J Med. 2012;366: 2466-73.

13. Lalani T, Chu VH, Park LP, Cecchi E, Corey GR, Durante-Mangoni E, et al; International Collaboration on Endocarditis-Prospective Cohort Study
Investigators. In-hospital and 1-year mortality in patients undergoing early surgery for prosthetic valve endocarditis. JAMA Intern Med. 2013;173:1495-504.

14. Li JS, Sexton DJ, Mick N, Nettles R, Fowler VG Jr, Ryan T, et al. Proposed modifications to the Duke criteria for the diagnosis of infective endocarditis Clin Infect Dis. 2000;30:633-8.

15. Clark RE. Definitions of terms of the Society of Thoracic Surgeons National Cardiac Surgery Database. Ann Thorac Surg. 1994;58:271-3.

16. Nashef SA, Roques F, Michel P, Gauducheau E, Lemeshow S, Salamon R. European system for cardiac operative risk evaluation (EuroSCORE). Eur J Cardiothorac Surg. 1999;16:9-13.

17. Grinda JM, Mainardi JL, D'Attellis N, Bricourt MO, Berrebi A, Fabiani JN, et al Cryopreserved aortic viable homograft for active aortic endocarditis. Ann Thorac Surg. 2005;79:767-71.

18. Kiefer T, Park L, Tribouilloy C, Cortes C, Casillo R, Chu V, et al Association between valvular surgery and mortality among patients with infective endocarditis complicated by heart failure. JAMA. 2011;306:2239-47.

19. Gaca JG, Sheng S, Daneshmand MA, O’Brien S, Rankin JS, Brennan JM, et al. Outcomes for endocarditis surgery in North America: a simplified risk scoring system. J Thorac Cardiovasc Surg. 2011;141:98-106. e101-2.

20. Musci M, Hübler M, Amiri A, Stein J, Kosky S, Meyer R, et al. Surgical treatment for active infective prosthetic valve endocarditis: 22-year single-centre experience. Eur J Cardiothorac Surg. 2010;38:528-38.

21. Grünenfelder J, Akins CW, Hilgenberg AD, Vlahakes GJ, Torchiana DF, Madsen JC, et al. Long-term results and determinants of mortality after surgery for native and prosthetic valve endocarditis. J Heart Valve Dis. 2001;10:694-702.

22. Moon MR, Miller DC, Moore KA, Oyer PE, Mitchell RS, Robbins RC, et al Treatment of endocarditis with valve replacement: the question of tissue versus mechanical prosthesis. Ann Thorac Surg. 2001;71:1164-71.

23. Gabbieri D, Dohmen PM, Linneweber J, Grubitzsch H, von Heymann C, Neumann K, et al. Early outcome after surgery for active native and prosthetic aortic valve endocarditis. J Heart Valve Dis. 2008;17:508-25.

24. David TE, Gavra G, Feindel CM, Regesta T, Armstrong S, Maganti MD. Surgica treatment of infective endocarditis: a continued challenge. $J$ Thorac Cardiovasc Surg. 2007;133:144-9.

25. Edwards MB, Ratnatunga CP, Dore CJ, Taylor KM. Thirty-day mortality and long-term survival following surgery for prosthetic endocarditis: a study from the UK heart valve registry. Eur J Cardiothorac Surg. 1998;14:156-64.

26. Avierinos JF, Thuny F, Chalvignac V, Giorgi R, Tafanelli L, Casalta JP, et al. Surgical treatment of active aortic infective endocarditis. Homografts are not the cornerstone of outcome. Ann Thorac Surg. 2007;84:1935-42.

27. Leyh RG, Knobloch K, Hagl C, Ruhparwar A, Fischer S, Kofidis T, et al Replacement of the aortic root for acute prosthetic valve endocarditis: prosthetic composite versus aortic allograft root replacement. J Thorac Cardiovasc Surg. 2004; $127: 1416-20$

28. Sabik JF, Lytle BW, Blackstone EH, Marullo AG, Pettersson GB, Cosgrove DM. Aortic root replacement with cryopreserved allograft for prosthetic valve endocarditis. Ann Thorac Surg. 2002;74:650-9.

29. Musci M, Weng Y, Hübler M, Amiri A, Pasic M, Kosky S, et al. Homograft aortic root replacement in native or prosthetic active infective endocarditis: twenty-year single-center experience. J Thorac Cardiovasc Surg. 2010;139:665-73. 